\title{
Treating Persistent Post-Concussive Symptoms with Photobiomodulation Therapy: Improvement in Cognition and Other Symptoms Both Subjectively and Objectively by ImPACT® Test.
}

\author{
Ronaldo Santiago ( $\nabla$ ronaldo@bioflexlaser.com ) \\ Meditech International Inc. \\ Jak Ozsarfati \\ Meditech International Inc. \\ Holly Shulman \\ Meditech International Inc. \\ Michael Zitney \\ Meditech International Inc.
}

\section{Research Article}

Keywords: Photobiomodulation therapy, post-concussion syndrome, mild traumatic brain injury, neurocognitive assessment

Posted Date: July 12th, 2021

DOI: https://doi.org/10.21203/rs.3.rs-671327/v1

License: (9) This work is licensed under a Creative Commons Attribution 4.0 International License.

Read Full License 


\section{Abstract}

\section{Objective:}

This research evaluates the use of Photobiomodulation Therapy (PBMT) as a viable treatment modality for post-concussion symptoms secondary to a traumatic brain injury and the use of the ImPACT ${ }^{\circledR}$ test to assess improvement in cognition and symptomatology in patients treated with PBMT.

\section{Background:}

Several studies have detailed the efficacy of PBMT as a treatment for concussions. As there are no widely accepted imaging or laboratory modalities that document concussive injuries, monitoring improvement objectively proves difficult. ImPACT ${ }^{\circledR}$ is a computer based neurocognitive assessment meant to measure cognitive performance for concussion injuries. This study uses ImPACT ${ }^{\circledR}$ as a means to document an improvement in symptomatology for patients with post-concussion symptoms.

\section{Methods:}

This retrospective study reviews patient performance in the $\operatorname{ImPACT}{ }^{\circledR}$ test in a cohort of 35 patients who are diagnosed with mild Traumatic Brain Injuries (mTBI) and experiencing post-concussive symptoms. Patient initially took the Post Injury 1 test then underwent PBMT therapy using the BIOFLEX DUO+ system three times a week for 4 weeks using approved parameters for treatment of the cervical spine soft tissue injuries. After the 4 week treatment, patients took the Post Injury 2 test and the results were compared.

\section{Results:}

By using PBM all the patients were improved clinically and their Post injury 2 ImPACT ${ }^{\circledR}$ test results were significantly better compared to their Post injury 1 ImPACT ${ }^{\circledR}$ test results.

\section{Conclusion:}

PBMT is an effective treatment modality for neurological rehabilitation in patients with Post-Concussion symptoms and ImPACT ${ }^{\circledR}$ is an appropriate and objective measure to monitor and assess improvement.

\section{Introduction}

Brain photobiomodulation therapy (PBMT) therapy is a well-established modality for treating many medical conditions. It is currently under investigation as a treatment for several different neurological disorders. ${ }^{1}$ This study reviews the use of PBMT in the treatment of post-concussive symptoms. We used the Immediate Post-Concussion Assessment and Cognitive Testing (ImPACT $®)$ tool to objectively assess patients' improvement in cognition and symptoms.

Traumatic brain injuries (TBI) have been labelled "a silent epidemic" by the Centers for Disease Control and Prevention (CDC). ${ }^{2}$ This is a devastating condition, which has and continues to affect young, 
previously healthy people. Even worse, concussion, considered a minor $\mathrm{TBI}$, can often go undiagnosed and thus untreated. An ever-growing number of professionals across Canada are working on preventing, diagnosing (the earlier the better) and treating concussion and their sequelae. Concussion, also called mild traumatic brain injury (mTBI), is an acute neurophysiological event related to traumatically induced blunt impact applied to the head and/or neck due to sudden acceleration, deceleration or rotational forces with a transient disturbance of brain function. ${ }^{3,4} \mathrm{mTBI}$ has often caused neurological, psychiatric and cognitive problems. Typically, patients with mTBI have suffered from headache, fatigue, dizziness, cognitive and memory impairment, depression, emotional outbursts/mood lability, impaired judgment, impulsivity, loss of executive skills, neck pain and sensitivity to environmental stimuli (light, sound, computer screens). ${ }^{5-8}$

Although most symptoms resolve in 1 to 3 weeks, approximately $5-43 \%$ of concussed individuals have experienced persistent symptoms lasting weeks or months. ${ }^{9,10}$ Post-concussion syndrome was a catchall term for the various persistent post-concussive symptoms and was previously accepted as a valid diagnosis. It was defined as the persistence of physical, cognitive, emotional, and sleep symptoms beyond the usual recovery period of 7 to 21 days after a concussion. ${ }^{11}$ Both the World Health Organization (WHO), and the Diagnostic and Statistical Manual of Mental Disorders (DSM) no longer contains a specific entry for post-concussion syndrome. Instead, the $11^{\mathrm{TH}}$ revision of the International Classification of Diseases (ICD-11) of the WHO captures persistent post-concussive symptoms under mild neurocognitive disorder, defined as a "subjective experience of a decline from a previous level of cognitive functioning, accompanied by objective evidence of impairment in performance on one or more cognitive domains"12 that may be attributable to several conditions, including trauma. The fifth edition of the DSM likewise reclassified post-concussion syndrome as major or mild neurocognitive disorder due to traumatic brain injury. The diagnostic criteria has specified that the neurocognitive disorder must persist beyond the "acute post-injury period" ${ }^{13}$

\section{Background And Rationale}

There has been no definitive treatment for persistent post-concussive symptoms. Previous suggested treatments focused primarily on alleviating individual symptoms and included antidepressants, antihypertensive and/or anti-epileptic agents, focused (including vestibular) rehabilitation, occupational therapy, psychotherapy and sleep therapy. ${ }^{14}$ This has led to interest in other healing alternatives such as PBMT.

\section{Photobiomodulation Therapy.}

The concept of PBMT, also called Low Level Laser Therapy, in its present form as a treatment for various disorders has been around since the 1960s. Cytochrome c oxidase (CCO) is a terminal enzyme of the electron transport chain that mediates the electron transfer from cytochrome $\mathrm{c}$ to molecular oxygen and therefore influences the mitochondrial membrane potential and the consequent processes that follow 
such as Adenosine Triphosphate (ATP) production and the release of Nitric Oxide (NO). ${ }^{15-18}$ Various studies has shown that pigments associated with $\mathrm{CCO}$ act as photoreceptors and responsive to a specific wavelength window in the electromagnetic spectrum, concentrated specifically within the visible red light ( $₫ 660 \mathrm{~nm})$ and invisible near infrared light (NIR) wavelengths $(\varangle 810 \mathrm{~nm}$ ). Within these wavelengths, light stimulation leads to increased production of ATP and the cascade of processes that accompanies this, from tissue repair, decreased inflammation and vasodilation. The effect of light, and PBMT specifically, on the mitochondria and at the cellular level is the basis for the wide application of PBMT in various disorders.

All traumatic brain injuries, regardless of the severity, can cause an increase in cerebral glucose uptake, a reduction of ATP levels and prolonged cerebral metabolic rate of glucose consumption (CMRglc) depression. ${ }^{19}$ This is accompanied by a decrease in cerebral blood flow (CBF) which can remain decreased for extended durations. Maugans et al. studied 12 children ages 11 to 15 who had a concussion secondary to a sports-related injury and showed that CBF, as measured by phase-contrast magnetic resonance angiography, was decreased relative to controls immediately after injury and that this decrease persisted beyond 30 days after injury even after symptoms resolved. ${ }^{20}$ Neural tissues contain large amounts of mitochondrial CCO. Red and NIR photonic energy modulates reactive oxygen species, activates mitochondrial DNA replication, increases early-response genes, increases growth factor expression, induces cell proliferation, and alters nitric oxide levels. ${ }^{21-23}$ Nitric oxide (released locally) increases regional cerebral blood flow. ${ }^{24}$ Wu et al. demonstrated that a single applications of 800-810 $\mathrm{nm}$ NIR light within four hours of injury resulted in a considerable improvement in neurological function. ${ }^{25}$

Many studies have shown neuroprotective effects of PBMT in many neurological disorders ${ }^{26-30}$ and some studies showed the benefits of red and NIR light applications in vivo in animals with experimental $\mathrm{TBI}^{31-33}$ Initial clinical studies of PBMT for persistent TBI symptoms in humans have been encouraging. For example, Naeser et al. investigated 11 chronic TBI cases with non-penetrating brain injury and showed that these patients had significant improvements with PBMT. ${ }^{34}$ Naeser et al. also reported on two patients with chronic TBI whose executive function and verbal memory were improved by midline and bilateral scalp application of red/NIR LED therapy. ${ }^{35}$

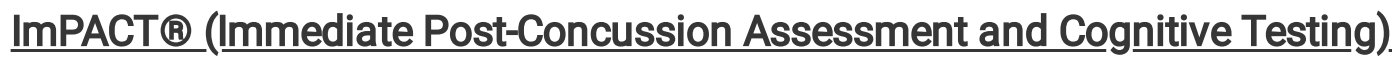

In competitive sports, as well as in rehabilitation, pain and neurological clinics, computer-based neurocognitive testing has become a principal component in the evaluation of concussion patients. ${ }^{36-}$ ${ }^{39}$ The most recognized computer-based neurocognitive assessment tool in North America is the Immediate Post-Concussion Assessment and Cognitive Testing (ImPACT ${ }^{\circledR}$ ) (ImPACT Applications Inc, Pittsburgh, Pennsylvania). ${ }^{40,41}$ ImPACT ${ }^{\circledR}$ test has been shown to be both reliable and valid for baseline and post-concussion assessment of neurocognitive function. ${ }^{42-44}$ The Meditech Rehabilitation Centre 
began implementing the ImPACT ${ }^{\circledR}$ test, specifically the Post-Injury test series, as a means of objectively assessing functional cognitive and symptom improvement in patients post-concussion.

The goal of this study is to review the use of PBMT alone as a viable treatment modality for postconcussive symptoms secondary to a mTBI. Subjective reporting and objective testing with the ImPACT ${ }^{\circledR}$ test to assess improvement in cognition and symptomatology in patients.

\section{Methodology}

In this retrospective study, patient files from January to December 2018 from a single clinical site in Toronto, Ontario, Canada (Meditech Rehabilitation Centre) were reviewed after receiving independent IRB approval. Inclusion criteria included patients between the ages of 15-65 years clinically diagnosed with a qualifying $\mathrm{mTBI}$ within at least 3 months of the traumatic incident with persistent post-concussion symptomatology and not currently undergoing any treatment. For reference, the clinical site used the previous International Classification of Diseases, Tenth Revision (ICD-10) clinical criteria for PostConcussion Syndrome defined as a "history of TBI and the presence of three or more of the following eight symptoms: 1) headache, 2) dizziness, 3) fatigue, 4) irritability, 5) insomnia, 6) concentration or 7) memory difficulty, and 8) intolerance of stress, emotion, or alcohol" 45 prior to the release of ICD-11 one year later. Patients who had any positive findings on cranial imaging studies, a diagnosis of or a family history of neuropsychiatric co-morbidity or any additional diagnoses compounding the diagnosis of a concussion or mTBI were excluded. As well, patients were excluded if they were undergoing other types of managed therapy with the exception of over the counter pain relievers.

In total, there were 35 patients eligible for this retrospective review, who were active patients from January to December 2018. The average age for our cohort of patients was 41 years old. $49 \%$ of patients were women and $51 \%$ of patients were men. All treatment and the ImPACT ${ }^{\circledR}$ test itself, were done in a single clinical site utilizing the same Bioflex® DUO+ laser system and parameters as detailed in Table 1. Patients are treated and tested in the same darkened room free of noise interruptions.

Following a history and physical examination, and prior to undergoing any treatment, the Post Injury Test 1 program of the Impact ${ }^{\circledR}$ test system was administered to each patient. After testing, patients underwent photobiomodulation using the Bioflex ${ }^{\circledR}$ DUO+ Laser Therapy system that uses a 180 bulb Light Emitting Diode (LED) array set followed by laser probes (Red AIGalnP Laser max power at 100mW; Infrared GaAlAs Laser max power at $200 \mathrm{~mW}$ ). Both delivery methods were applied using four arranged placements to the cervical spine and six placements to the cranial area (three placements each side), and both entailed the use of red light at $660 \mathrm{~nm}$ wavelength and near-infrared light at 830-840 nm wavelength. Treatment was provided three times per week on alternating days with weekends off for four weeks for a total of 12 treatments using a gradually increasing dosing scale wherein increasing power dosage and modulation is applied every week per the schedule adopted in Table 1. 
At the end of the 12 weeks, all patients took a second ImPACT $®$ test (Post Injury 2 test) and the results were compared with Post Injury 1. Clinically, all patients' conditions were improved after 12 treatments.

\section{Statistical Analysis}

SPSS Version 25 was used to perform all statistical tests. These included descriptive statistics (mean, median, skewness, etc.), paired sample t-tests and Wilcoxon signed rank tests. Both parametric and nonparametric statistics were employed as the data collected, from the ImPACT ${ }^{\circledR}$ test, consisted of different data types. The Wilcoxon signed rank test has been used to compare health outcomes; specifically, if there has been an improvement between the first ImPACT ${ }^{\circledR}$ test and the second ImPACT ${ }^{\circledR}$ test with PBMT.

The data was first exported from the ImPACT ${ }^{\circledR}$ system into Microsoft Excel. In Excel, the dataset was cleaned to ensure that each patient was only recorded once, and every variable is listed as test 1 (preintervention) and test 2 (post-intervention) to facilitate the statistical testing. Any extraneous and personal information that would lead to the identification of the patient was removed. A unique patient identifier was created.

A paired t-test was used to evaluate the changes in the sample population scores between pre- and posttreatment intervention. The Wilcoxon signed rank test was used to calculate the difference between the pre-intervention and post-intervention scores for the same participants. Importantly, the data being normally distributed is not a condition of a Wilcoxon signed rank test, even though it is for the t-test. A Wilcoxon signed rank test can be considered the nonparametric version of a paired t-test. Thus, the two statistical tests employed were complementary to one another.

As a component of the ImPACT ${ }^{\circledR}$ test, the patient ranked their symptoms on a scale of 1 to 6 . This type of nonparametric hypothesis test can demonstrate that if the alternative hypothesis is correct - there are more positive differences after treatment $(\alpha=0.05)$ - then the treatment was successful in helping the patient. SPSS automatically calculates the rank for the difference in scores between test 1 (preintervention) and test 2 (post-intervention) for each variable being examined. The smallest difference would receive a rank of one and the largest difference would receive $n$. If the difference scores were tied at any point, then they would receive the same rank regardless if it was a positive or negative difference. After each of the differences has been calculated, SPSS also attaches a positive or negative sign to each rank based on the absolute difference between test 1 and test 2 .

Table 1 PBMT dosage and treatment schedule 


\section{Week 1}

\begin{tabular}{|c|c|c|c|c|c|c|c|}
\hline $\begin{array}{l}\text { Treatment } \\
\text { Head } \\
\text { Wavelength }\end{array}$ & $\begin{array}{l}\text { Frequency } \\
\text { (Hz } 5 \mu \mathrm{s} \\
\text { resolution) }\end{array}$ & $\begin{array}{l}\text { Duty } \\
\text { Cycle } \\
(10 \% \\
\text { steps) }\end{array}$ & $\begin{array}{l}\text { Duration } \\
\text { (sec) }\end{array}$ & $\begin{array}{l}\text { Average } \\
\text { Power } \\
\text { Output } \\
\text { (mW) }\end{array}$ & $\begin{array}{l}\text { Power } \\
\text { Density } \\
\left(\mathrm{mW} / \mathrm{cm}^{2}\right)\end{array}$ & $\begin{array}{l}\text { Energy } \\
(J)\end{array}$ & $\begin{array}{l}\text { Energy } \\
\text { Density } \\
\left(\mathrm{J} / \mathrm{cm}^{2}\right)\end{array}$ \\
\hline \multicolumn{8}{|l|}{$\begin{array}{l}\text { Static LED } \\
\text { Arrays** }\end{array}$} \\
\hline $660 \mathrm{~nm}$ & $C W * \star \star$ & & 300 & 750 & 10 & 225 & 3 \\
\hline 840 nm & 20 & 40 & 360 & 600 & 8 & 216 & 2.88 \\
\hline $\begin{array}{l}\text { Kinetic Spot } \\
\text { Laser } \\
\text { Diodes** }\end{array}$ & 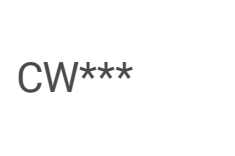 & & 7 & 75 & 750 & 0.525 & 5.25 \\
\hline $\begin{array}{l}660 \mathrm{~nm} \\
(100 \% \\
\text { power) }\end{array}$ & & & & & & & \\
\hline
\end{tabular}

Week 2

\begin{tabular}{|c|c|c|c|c|c|c|c|}
\hline $\begin{array}{l}\text { Treatment } \\
\text { Head } \\
\text { Wavelength }\end{array}$ & $\begin{array}{l}\text { Frequency } \\
\text { (Hz } 5 \mu s \\
\text { resolution) }\end{array}$ & $\begin{array}{l}\text { Duty } \\
\text { Cycle } \\
\text { (10\% } \\
\text { steps) }\end{array}$ & $\begin{array}{l}\text { Duration } \\
\text { (sec) }\end{array}$ & $\begin{array}{l}\text { Average } \\
\text { Power } \\
\text { Output } \\
\text { (mW) }\end{array}$ & $\begin{array}{l}\text { Power } \\
\text { Density } \\
\left(\mathrm{mW} / \mathrm{cm}^{2}\right)\end{array}$ & $\begin{array}{l}\text { Energy } \\
(J)\end{array}$ & $\begin{array}{l}\text { Energy } \\
\text { Density } \\
\left(\mathrm{J} / \mathrm{cm}^{2}\right)\end{array}$ \\
\hline $\begin{array}{l}\text { Static LED } \\
\text { Arrays }{ }^{\star}\end{array}$ & & & & & & & \\
\hline $660 \mathrm{~nm}$ & $C W \pi x$ & & 300 & 150 & 10 & $2 Z 5$ & 3 \\
\hline $840 \mathrm{~nm}$ & 50 & 50 & 360 & 750 & 10 & 270 & 3.6 \\
\hline $\begin{array}{l}\text { Kinetic Spot } \\
\text { Laser }\end{array}$ & $C W^{\star \star \star \star}$ & & 7 & 75 & 750 & 0.525 & 5.25 \\
\hline $\begin{array}{l}660 \mathrm{~nm} \\
(100 \% \\
\text { power) }\end{array}$ & 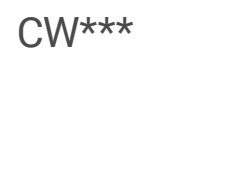 & & 7 & 135 & 1350 & 0.945 & 9.45 \\
\hline $\begin{array}{l}825 \mathrm{~nm} \\
\text { ( } 75 \% \text { power) }\end{array}$ & & & & & & & \\
\hline
\end{tabular}

Week 3 


\begin{tabular}{|c|c|c|c|c|c|c|c|}
\hline $\begin{array}{l}\text { Treatment } \\
\text { Head } \\
\text { Wavelength }\end{array}$ & $\begin{array}{l}\text { Frequency } \\
\text { (Hz } 5 \text { us } \\
\text { resolution) }\end{array}$ & $\begin{array}{l}\text { Duty } \\
\text { Cycle } \\
\text { (10\% } \\
\text { steps) }\end{array}$ & $\begin{array}{l}\text { Duration } \\
\text { (sec) }\end{array}$ & $\begin{array}{l}\text { Average } \\
\text { Power } \\
\text { Output } \\
\text { (mW) }\end{array}$ & $\begin{array}{l}\text { Power } \\
\text { Density } \\
\left(\mathrm{mW} / \mathrm{cm}^{2}\right)\end{array}$ & $\begin{array}{l}\text { Energy } \\
\text { (J) }\end{array}$ & $\begin{array}{l}\text { Energy } \\
\text { Density } \\
\left(\mathrm{J} / \mathrm{cm}^{2}\right)\end{array}$ \\
\hline $\begin{array}{l}\text { Static LED } \\
\text { Arrays* }\end{array}$ & & & & & & & \\
\hline $660 \mathrm{~nm}$ & $C W^{\star \star \star *}$ & & 300 & 750 & 10 & 225 & 3 \\
\hline $840 \mathrm{~nm}$ & 50 & 70 & 360 & 1050 & 14 & 378 & 5.04 \\
\hline $\begin{array}{l}\text { Kinetic Spot } \\
\text { Laser } \\
\text { Diodes** }\end{array}$ & $C W^{\star \star \star}$ & & 7 & 75 & 750 & 0.525 & 5.25 \\
\hline $\begin{array}{l}660 \mathrm{~nm} \\
(100 \% \\
\text { power) }\end{array}$ & $C W^{* * *}$ & & 7 & 180 & 1800 & 1.26 & 12.6 \\
\hline $\begin{array}{l}825 \mathrm{~nm} \\
(100 \% \\
\text { power) }\end{array}$ & & & & & & & \\
\hline
\end{tabular}

\section{Week 4}

\begin{tabular}{|c|c|c|c|c|c|c|c|}
\hline $\begin{array}{l}\text { Treatment } \\
\text { Head } \\
\text { Wavelength }\end{array}$ & $\begin{array}{l}\text { Frequency } \\
\text { (Hz } 5 \mu s \\
\text { resolution) }\end{array}$ & $\begin{array}{l}\text { Duty } \\
\text { Cycle } \\
\text { (10\% } \\
\text { steps) }\end{array}$ & $\begin{array}{l}\text { Duration } \\
\text { (sec) }\end{array}$ & $\begin{array}{l}\text { Average } \\
\text { Power } \\
\text { Output } \\
\text { (mW) }\end{array}$ & $\begin{array}{l}\text { Power } \\
\text { Density } \\
\left(\mathrm{mW} / \mathrm{cm}^{2}\right)\end{array}$ & $\begin{array}{l}\text { Energy } \\
(J)\end{array}$ & $\begin{array}{l}\text { Energy } \\
\text { Density } \\
\left(\mathrm{J} / \mathrm{cm}^{2}\right)\end{array}$ \\
\hline $\begin{array}{l}\text { Static LED } \\
\text { Arrays** }\end{array}$ & & & & & & & \\
\hline $660 \mathrm{~nm}$ & 100 & 90 & 300 & 675 & 9 & 202.5 & 2.7 \\
\hline $840 \mathrm{~nm}$ & 50 & 70 & 360 & 1050 & 14 & 378 & 5.04 \\
\hline $\begin{array}{l}\text { Kinetic Spot } \\
\text { Laser }\end{array}$ & $C W^{\star \star \star \star}$ & & 7 & 75 & 750 & 0.525 & 5.25 \\
\hline $\begin{array}{l}660 \mathrm{~nm} \\
(100 \% \\
\text { power) }\end{array}$ & $C W^{\star \star \star \star}$ & & 7 & 180 & 1800 & 1.26 & 12.6 \\
\hline $\begin{array}{l}825 \mathrm{~nm} \\
\text { (100\% } \\
\text { power) }\end{array}$ & & & & & & & \\
\hline
\end{tabular}

*DUO+Arrays: $\quad$ RED 180 LEDs, wavelength $660 \mathrm{~nm}$. Spot size $75 \mathrm{~cm}^{2}$

IR (Infrared) 180 LEDs, wavelength $830 \mathrm{~nm}$. Spot Size: $75 \mathrm{~cm}^{2}$

** Laser Probes (spot treatment 7 seconds per point across areas covered by arrays): 
RED, wavelength $660 \mathrm{~nm}$. Spot Size: $0.10 \mathrm{~cm}^{2}$

IR (Infrared), wavelength $825 \mathrm{~nm}$. Spot Size: $0.10 \mathrm{~cm}^{2}$

${ }^{\star * \star} \mathrm{CW}-$ Continuous Wave Mode / Unpulsed

The Wilcoxon signed rank test and the paired sample t-test were used to statistically compare between pre-intervention and post-intervention for all variables being evaluated. All statistically significant results have been included below.

\section{Results}

By using PBMT all the patients improved clinically and their Post injury 2 ImPACT ${ }^{\circledR}$ test results were significantly better, compared to their Post injury 1 ImPACT ${ }^{\circledR}$ test results.

\section{T-test Results}

The Cognitive Efficiency Index (CEI) was statistically significant at the 95\% confidence level, specifically 0.007. Therefore, at the $95 \%$ confidence level there is improvement between the CEl calculated at the patients' pre-intervention treatment and post-intervention treatment.

\section{Wilcoxon Signed Rank Test}

Table 2: Significant Wilcoxon Signed Rank Measures from the ImPACT ${ }^{\circledR}$ test 


\begin{tabular}{|lllll|}
\hline Relationship & $\begin{array}{l}\text { Mean of Pre- } \\
\text { intervention Score } \pm \text { SD }\end{array}$ & $\begin{array}{l}\text { Mean of Post } \\
\text { Intervention Score } \pm \text { SD }\end{array}$ & $\begin{array}{c}\text { Rank } \\
\text { Sum Z }\end{array}$ & $\begin{array}{c}\text { Rank } \\
\text { Sum P }\end{array}$ \\
\hline Total Symptom Score & $41.57 \pm 24.188$ & $25.49 \pm 21.228$ & -4.473 & 0.000 \\
\hline $\begin{array}{l}\text { Colour Match Average } \\
\text { Correct }\end{array}$ & $0.873 \pm 0.194$ & $0.809 \pm 0.184$ & -3.255 & 0.001 \\
\hline Verbal Composite Score & $80.09 \pm 13.656$ & $84.83 \pm 11.663$ & -3.085 & 0.002 \\
\hline $\begin{array}{l}\text { Visual Motor Speed } \\
\text { Composite Score }\end{array}$ & $33.054 \pm 8.091$ & $35.681 \pm 7.215$ & -3.096 & 0.002 \\
\hline $\begin{array}{l}\text { Reaction Time } \\
\text { Composite Score }\end{array}$ & $0.735 \pm 0.181$ & $0.685 \pm 0.173$ & -2.410 & 0.016 \\
\hline $\begin{array}{l}\text { Three Letters Total } \\
\text { Sequence Correct }\end{array}$ & $3.80 \pm 1.451$ & $4.51 \pm 1.173$ & -3.097 & 0.002 \\
\hline $\begin{array}{l}\text { Three Letters Total } \\
\text { Letters Correct }\end{array}$ & $12.46 \pm 3.913$ & $13.74 \pm 3.364$ & -2.820 & 0.005 \\
\hline $\begin{array}{l}\text { Three Letters Per Letter } \\
\text { Correct }\end{array}$ & $0.830 \pm 0.261$ & $0.916 \pm 0.224$ & -2.995 & 0.003 \\
\hline $\begin{array}{l}\text { Three Letters Average } \\
\text { Counted }\end{array}$ & $13.731 \pm 4.333$ & $14.971 \pm 4.232$ & -2.990 & 0.003 \\
\hline $\begin{array}{l}\text { Three Letters Average } \\
\text { Counted Correct }\end{array}$ & $13.440 \pm 4.544$ & $14.834 \pm 4.193$ & -3.163 & 0.002 \\
\hline
\end{tabular}

Table 2 has illustrated all significant measures at the 95\% confidence level. The symptom score presented summary information regarding the individual's self-reported symptom data. A higher score reflected a higher symptom total. ${ }^{46}$ The mean for the second total symptom (25.49) score was less than the first total symptom score (41.57). Colour Match in the ImPACT ${ }^{\circledR}$ system measured the reaction time in correctly matching a word with the corresponding colour ink. ${ }^{46}$ The average colour match results improved from pre-intervention to post-intervention and thus were significant at the $95 \%$ confidence level.

The Verbal Memory Composite Score used Word Memory Total Percent Correct, Symbol Match Total Correct Hidden, and Three Letters Percent Total Letters Correct together, by adding these three values and dividing by three. This composite score was designed to evaluate vocabulary attention span, learning and memory. ${ }^{46}$ The Verbal Composite Score had a higher positive rank sum (453.0) than negative rank sum (108.0). The Reaction Time Composite, an average of Average Correct RT from X's and O's section, Symbol Match Average Correct RT Visible/3 and Color Match Average Correct RT, had a greater negative sum rank (392.50) than positive sum rank (13.5.50). The Visual Motor Speed Composite Score was designed to "evaluate visual processing, learning and memory, and visual-motor response speed". ${ }^{46}$ This composite score uses the Total Number Correct/4 from the $\mathrm{X}$ and $\mathrm{O}$ section of the ImPACT ${ }^{\circledR}$ Test and the Average Counted Correctly from the Three Letters section. These two scores were added together and 
then divided by two. The Visual Motor Speed Composite Measure had a higher positive rank sum (504.0) than negative rank sum (126.0).

The Three Letters module of the ImPACT ${ }^{\circledR}$ test measured memory and eye-hand coordination speed. ${ }^{46}$ In this section of the test, the patient was instructed to click backwards on numbers from 25 in a 5 by 5 grid and then shown three consonants. The patient was then instructed to click backwards from 25 again and then the patient was asked to recall the three consonants displayed just previous. This section is repeated 5 times.

Table 3: Three Letters Sum of Ranks from the Wilcoxon Signed Rank Test

\begin{tabular}{|lcl|}
\hline Measure & Sum of Ranks - Negative & Sum of Ranks - Positive \\
\hline Three Letters Total Sequence Correct & 21.00 & 169.00 \\
\hline Three Letters Total Letters Correct & 30.00 & 180.00 \\
\hline Three Letters Per Letter Correct & 25.00 & 185.00 \\
\hline Three Letters Average Counted & 132.50 & 497.50 \\
\hline Three Letters Average Counted Correct & 122.00 & 508.00 \\
\hline
\end{tabular}

Table 3 has demonstrated the positive and negative sum of ranks calculated as part of the Wilcoxon signed rank test. In all instances, the positive sums were greater than the negative sums at the $95 \%$ confidence level.

\section{Discussion}

The Centers for Disease Control and Prevention (CDC) estimated that about 2.87 million TBI-related emergency department (ED) visits, hospitalizations, and deaths occurred in $2014 .{ }^{47}$ The current estimates of the sports-related concussions and brain injuries in the US are 1.6-3.8 million every year. ${ }^{48}$ The annual percent change was reported by Rao et al as 9.6 (95\% Cl 8.2- 11.0) for all ages, 10.3 (95\% Cl 2.5-18.1) for youth and 9.7 (95\% Cl 9.4-10.0) for adults between 2005 and 2014, which showed an increased incidence of TBIs in Canada. According to the same study, the proportion of Canadians who reported having a TBI in 2014 more than doubled to $3.2 \%$, compared to $1.4 \%$ in 2005 . There were approximately 155,000 TBI cases in 2014 in Canada. ${ }^{49}$

Patients with a mTBI do not show any evidence of intracranial pathologies such as bleeding, subdural or epidural hematoma and/or cranial fracture on standard imaging. ${ }^{50}$ Recent studies have shown that mTBI can cause functional neuronal disruption and structural damage in humans and animals. Due to a cerebral energy imbalance, these disruptions have the potential to manifest a wide clinical spectrum, ranging from subtle cognitive deficits only detectable on neuropsychological testing to overt neurological and behavioral symptoms. ${ }^{14,51}$ 
Although full recovery is expected within three months after concussion/mTBI, there has been a small group of concussion sufferers that have experienced persistent symptoms. A number of factors can influence the rate of recovery, including the mechanism and setting for the initial injury, age, and recurrent concussion incidents in the past. A typical mTBI patient at the Meditech Rehabilitation Centre would have had a concussion three or more months prior to initial presentation, and had already consulted a barrage of healthcare practitioners, including their family physicians, a neurologist, a physiotherapist and others, with no relief in their symptoms. All 35 patients noted improvement in their cognitive functions after PBMT.

PBMT has often been used 'off label' as a treatment modality for post-concussion symptoms secondary to TBI. Although most PBMT devices are generally classified and licensed as general wellness devices without public health oversight, Meditech Rehabilitation Centre uses the BIOFLEX® DUO+ system, which has Health Canada and FDA cleared treatment indications for soft tissue injuries, minor pains and to increase local blood flow. Meditech Rehabilitation Centre has been treating patients for specific postconcussive symptoms like neck pain and stiffness for several years as a supporting regimen to traditional therapies. At Meditech Rehabilitation Centre, a number of patients have reported improvement in concussion symptoms using our BIOFLEX ${ }^{\circledR}$ DUO+ devices after traditional treatment methods proved less successful.

The Biphasic Dose Response

A major concern in the acceptance of PBMT for the treatment of neurological conditions is the use of appropriate and effective dosage. In many cases, especially in our own clinical observations, it has been found in PBMT that more light is not necessarily therapeutically better than less light in terms of energy delivery. This "biphasic dose responses (also called Arndt-Schulz law or hormesis)" shows that PBMT can simultaneously inhibit and stimulate, and the techniques and settings for consistently achieving these effects have not always been clearly stated. ${ }^{52}$ Because of this, certain studies that utilize a static dosing mechanism in PBMT for the treatment of neurological conditions either mention no effect, or on occasion, certain uncomfortable side effects such as headaches. Being cognizant of the biphasic dose response so typical in PBMT, treatment in Meditech Rehabilitation Centre is provided in a gradually increasing dosing fashion, first starting with a relatively mild dose with continuous light application before gradually increasing the energy density application (in Joules $/ \mathrm{cm}^{2}$ ) and adding pulse modulation in weekly intervals. Despite the parameters used in this study, in clinical practice the patient's response and their capacity to follow-up were taken into consideration. This gradual dosing pattern allows tissues to adjust to the treatment and absorb more photons of light as treatment progresses while maintaining depth penetration. ${ }^{53}$

Of note, in this study, was the dual treatment modality, in which both the cervical area and parts of the cranium were treated. Most studies that have used PBMT for the treatment of neurological conditions tended to focus treatment only in the cranial area. ${ }^{26,27,31,32,35,54-56}$ The inclusion of the cervical area treatment has demonstrated that PBMT can cause vasodilation and increased local circulation and can 
have a potential effect on certain neurotransmitters like serotonin (5-HT) and cholinesterase levels. ${ }^{57}$ Although most studies show that at most cranial penetration of most PBMT devices are minimal (up to 4 $\mathrm{cm}$ at most, based on cadaver studies) ${ }^{58}$ including cervical treatments has been instrumental in cognitive improvement due to the effect of increased cerebral circulation. ${ }^{59}$

\section{The ImPACT $®$ test with PBMT}

The ImPACT ${ }^{\circledR}$ test included six tests/modules (i.e., word discrimination, design memory, $x$ 's and o's, symbol match, color match, three letters) that yielded five composite/domain scores (i.e., verbal memory, visual memory, visual motor skills, reaction time, and impulse control). For the verbal memory, visual memory, visual-motor skills, and reaction time composite scores, demographically adjusted percentile scores (i.e., age and sex) were provided on the standard clinical report printout. Demographically adjusted percentile scores for the impulse control composite score were computed from the normative data tables available from the test publisher. ${ }^{46}$ The BIOFLEX® DUO+ PBMT intervention was effective in improving patients' scores for several of the ImPACT ${ }^{\circledR}$ test categories including: Color Match, Verbal Composite Score, Visual Composite Score and Visual Motor Speed and Reaction Time.

The Cognitive Efficiency Index (CEI) is a measure tabulated from the Symbol Match section of the ImPACT ${ }^{\circledR}$ test. It was calculated based on the speed and accuracy of items clicked correctly. This was just one metric; however, it should not be considered an overall concussion severity index nor has it been validated for that purpose. The ImPACT ${ }^{\circledR}$ test has removed the $\mathrm{CEI}$ in its newest streamlined version 4 format released in 2021 and has replaced it with the Two Factor score ${ }^{46}$. However, given the significance of this measure at the $95 \%$ confidence level, we have decided to still include the CEI in the results as a report of its utility.

The CDC divides mTBI symptoms into 4 categories: Thinking/Remembering, Sleep, Emotional/Mood, and Physical. ${ }^{60}$ Aside from the objective and rapid measurement of cognitive abilities, ImPACT $\circledast$ included a subjective symptom reporting scale. The ImPACT post-concussion symptom rating scale contained 22 somatic, affective, and cognitive symptoms, with each symptom being rated from 0 (none) to 6 (severe). Two values can be computed for the symptom questionnaire: total symptom score (sum of all ratings for all symptoms) and the number of symptoms endorsed as being present (regardless of the severity). Both of these values were examined for this study. The patients' symptoms decreased significantly at the $95 \%$ confidence level, for patients after receiving PBMT with the BIOFLEX® DUO+ system. The Wilcoxon Signed Rank tests detailed the decrease in the total symptom score. Thus, patients were experiencing less symptoms after the intervention than without it.

Improvement in the objective and subjective scores of the ImPACT ${ }^{\circledR}$ test after treatment with PBMT showed that computer-based neurocognitive assessments can be considered a valuable aid in diagnosis and assessment of treatment response for mTBI patients with persistent post-concussive symptoms.

\section{LIMITATIONS:}


There were limitations to this study. Specifically, the sample size was small, and the treatment time was limited to one month. In clinical practice, further improvement was noted beyond the one month period, and some patients had decided to continue treatment at home utilizing portable devices. Given that the consistency of use of portable devices cannot be controlled for, we decided not to include these in our study. Increasing sample sizes, extending the treatment period, and including cerebral blood flow measurement could potentially provide additional evidence of cognitive improvement utilizing PBMT.

\section{RECOMMENDATIONS:}

Our group did not initiate an ImPACT $®$ baseline examination for this population given that they have already suffered an injury prior to their first presentation. Doing a baseline ImPACT $®$ test measurement under controlled conditions may have provided a better assessment of a person's cognitive state preconcussion and a better comparison of improvement with the Post Injury 1 and 2 tests. Initiating a study with the baseline measurements for certain concussion-prone population groups, i.e., hockey players, members of the armed forces, construction workers, may prove to be a valid option for a future study.

\section{Conclusion}

Concussion with persistent post-concussive symptoms is a severe health problems which has significant functional and economic implications for the patient, their relatives, school, employers, and organizations like the Office of Workers' Compensation Programs (OWCP) of the United States Department of Labor and the Workplace Safety and Insurance Board (WSIB) of Ontario, Canada. Available studies using symptom based questionnaires suggested that patients with post-concussive symptoms have lower perceived levels of overall quality of life, ${ }^{61,62}$ are less likely to immediately return to work and more likely to receive health related benefits. ${ }^{63}$ Patients with persistent post-concussive symptoms will need school or work-place accommodations to restrict or modify cognitive loads until recovery, which can be long, slow and frustrating for patients and severely affects their daily life endeavours. ${ }^{64}$ Our study has shown that PBMT is an effective treatment modality for neurological rehabilitation in patients with postconcussive symptoms as assessed using the ImPACT ${ }^{\circledR}$ test, leading to improved cognitive performance and an improvement in symptomatology. PBMT should be considered one of the available options in the treatment of concussions and persistent post-concussive symptoms.

\section{Declarations}

\section{Ethics Approval and Consent to Participate:}

This study is reviewed and approved by an independent Institutional Review Board (IRB) Advarra (6100 Merriweather Drive, Suite 600 Columbia MD 21044). The IRB granted a Waiver of Consent, Assent and Parental Consent for this study.

\section{Consent for Publication:}


Not applicable.

\section{Availability of Data and Material:}

The datasets used and/or analysed during the current study are not publicly available due to confidentiality laws but are available from the corresponding author on reasonable request.

\section{Competing Interests:}

$\mathrm{MZ}$ is the Medical Director of Meditech Rehabilitation Centre. RS and JO are employed full time as clinical research staff in Meditech Rehabilitation Centre. $\mathrm{HO}$ is a research volunteer with Meditech Rehabilitation Centre. Meditech International is the parent company of Meditech Rehabilitation Centre and manufactures BIOFLEX® DUO+ devices. The authors do not own any shares or investment in Meditech International.

\section{Funding:}

The authors received no financial support for the research, authorship, and/or publication of this article.

\section{Authors' Contributions:}

R.S., J.O., and H.S. wrote the main manuscript text. R.S. and J.O. compiled patient treatment information and test results. H.S. provided data analysis. M.Z. provided final editing. All authors reviewed the final manuscript

\section{Acknowledgement:}

We would like to offer acknowledgement to Dr. Fred Kahn, President and CEO of Meditech International and Vyacheslav Kim, Clinic Manager of Meditech International who supervised and directed treatment.

\section{References}

1. Salehpour F, Mahmoudi J, Kamari F, et al. Brain photobiomodulation therapy: a narrative review. Mol Neurobiol. 2018 Aug;55(8):6601-6636.

2. Faul M, Xu, L, Wald, MM, et al. Traumatic Brain Injury in the United States: Emergency Department Visits, Hospitalizations and Deaths 2002-2006. Atlanta, GA: Centers for Disease Control and Prevention, National Center for Injury Prevention and Control.

3. Shrey DW, Griesbach GS, Giza CC. The pathophysiology of concussions in youth. Phys Med Rehabil Clin N Am. 2011 Nov;22(4):577-602, vii.

4. Barkhoudarian G, Hovda DA, Giza CC. The molecular pathophysiology of concussive brain injury. Clin Sports Med. 2011;30(1):33-48, vii-iii.

5. Vaishnavi S, Rao V, Fann JR. Neuropsychiatric problems after traumatic brain injury: unraveling the silent epidemic. Psychosomatics. 2009;50(3):198-205. 
6. Kashluba S, et al. Neuropsychologic and functional outcome after complicated mild traumatic brain injury. Ach Phys Med Rehabil. 2008;89(5):904-911.

7. Kennedy JE, Jaffee MS, Leskin GA, et al. Posttraumatic stress disorder and posttraumatic stress disorder-like symptoms and mild traumatic brain injury. J Rehabil Res Dev. 2007;44(7):895-920.

8. Polinder S, Cnossen MC, Real RGL, et al. A multidimensional approach to post-concussion symptoms in mild traumatic brain injury. Front Neurol. 2018; 9:1113

9. Bazarian J.J., Wong T., Harris M., et al. Epidemiology and predictors of post-concussive syndrome after minor head injury in an emergency population. Brain Inj. 1999 Mar;13(3):173-189

10. Iverson G.L. Outcome from mild traumatic brain injury. Curr. Opin. Psychiatry. 2005 May; 18, 301317.

11. Carroll LJ, Cassidy JD, Peloso PM, et al. Prognosis for mild traumatic brain injury: results of the WHO Collaborating Centre Task Force on Mild Traumatic Brain Injury. J Rehabil Med. 2004;(43 Suppl):84105.

12. World Health Organization. International statistical classification of diseases and related health problems (11th ed.). https://icd.who.int/. (2019, accessed 26 April 2021).

13. American Psychiatric Association. Diagnostic and statistical manual of mental disorders (5th ed.). https://doi.org/10.1176/appi.books.9780890425596. (2013, accessed 26 April, 2021)

14. Tator $\mathrm{CH}$. Concussions and their consequences: current diagnosis, management and prevention. CMAJ. 2013;185:975-979.

15. Wang $X$, Tian F, Soni S, et al. Interplay between up-regulation of cytochrome-c-oxidase and hemoglobin oxygenation induced by near-infrared laser. Sci Rep. 2016; 6: 30540.

16. Hamblin M. Mechanisms and Mitochondrial Redox Signaling in Photobiomodulation. Photochem Photobiol, 2018, 94: 199-212.

17. Lanzafame R. Light Dosing and Tissue Penetration: It Is Complicated. Photobiomodul Photomed Laser Surg. July 2020; 38(7): 393-394.

18. Zein R, Selting W, Hamblin M. Review of light parameters and photobiomodulation efficacy: dive into complexity. J. of Biomedical Optics. 2018;23(12):120901

19. Maugans TA, Farley C, Altaye $M$, et al. Pediatric sports-related concussion produces cerebral blood flow alterations. Pediatrics. 2012 Jan;129(1):28-37.

20. Mester E, Szende B, Tota JG. Effect of laser on hair growth of mice. Kiserl Orvostud. 1967; 19:628631.

21. Chung H, Dai T, Sharma SK, et al. The nuts and bolts of low-level laser (light) therapy. Ann Biomed Eng. 2012;40(2):516-533.

22. Wu HM, Huang SC, Vespa P, et al. Redefining the pericontusional penumbra following traumatic brain injury: evidence of deteriorating metabolic derangements based on positron emission tomography. $J$ Neurotrauma. 2013;30(5):352-360. 
23. Ando T, Xuan W, Xu T, et al. Comparison of therapeutic effects between pulsed and continuous wave 810-nm wavelength laser irradiation for traumatic brain injury in mice. PLoS One 2011;6(10):e26212

24. Ilic S, Leichliter S, Streeter J, et al. Effects of power densities, continuous and pulse frequencies, and number of sessions of low-level laser therapy on intact rat brain. Photomed Laser Ther 2006; 24(4):458-466.

25. Wu Q, Xuan W, Ando T, et al. Low-level laser therapy for closed-head traumatic brain injury in mice: effect of different wavelengths. Lasers Surg Med. 2012; 44:218-226.

26. Schiffer F, Johnston AL, Ravichandran C, et al. Psychological benefits 2 and 4 weeks after a single treatment with near infrared light to the forehead: A pilot study of 10 patients with major depression and anxiety. Behav Brain Funct 2009;5(1):46.

27. Salehpour F, Rasta SH. The potential of transcranial photobiomodulation therapy for treatment of major depressive disorder. Rev Neurosci 2017;28(4):441-453.

28. da Silva T, da Silva FC, Gomes AO, et al. Effect of photobiomodulation treatment in the sublingual, radial artery region, and along the spinal column in individuals with multiple sclerosis: Protocol for a randomized, controlled, double-blind, clinical trial. Medicine. 2018 May;97(19):e0627.

29. Rojas JC, Bruchey AK, Gonzalez-Lima F. Low-level light therapy improves cortical metabolic capacity and memory retention. J Alzheimers Dis 2012;32(3):741-752.

30. Hamblin MR. Shining light on the head: Photobiomodulation for brain disorders. BBA Clin. 2016 Oct $1 ; 6: 113-124$.

31. Xuan W, Vatansever F, Huang L, et al. Transcranial low-level laser therapy improves neurological performance in traumatic brain injury in mice: effect of treatment repetition regimen. PLoS One. 2013;8(1):e53454.

32. Oron A, Oron U, Streeter J, et al. Low-level laser therapy applied transcranially to mice following traumatic brain injury significantly reduces long-term neurological deficits. J Neurotrauma. 2007 Apr;24(4):651-6.

33. Xuan W, Agrawal T, Huang L, et al. Low-level laser therapy for traumatic brain injury in mice increases brain derived neurotrophic factor (BDNF) and synaptogenesis. J Biophotonics. 2015 Jun;8(6):502-11.

34. Naeser MA, Zafonte R, Krengel MH, et al. Significant improvements in cognitive performance posttranscranial, red/near-infrared light-emitting diode treatments in chronic, mild traumatic brain injury: Open-protocol study. J Neurotrauma 2014;31(11):1008-17.

35. Naeser MA, Saltmarche A, Krengel MH, et al. Improved cognitive function after transcranial, lightemitting diode treatments in chronic, traumatic brain injury: two case reports. Photomed Laser Surg. $2011 ; 29,351-358$.

36. Schatz P, Zillmer EA. Computer-based assessment of sports-related concussion. Appl Neuropsychol. 2003;10:42-47.

37. Schatz P, Browndyke J. Applications of Computer-based Neuropsychological Assessment. J Head Trauma Rehabil. 2002 Oct;17(5):395-410. 
38. Fazio VC, et al. The relation between post concussion symptoms and neurocognitive performance in concussed athletes. NeuroRehabilitation. 2007;22:207-216.

39. Meehan WP 3rd, d'Hemecourt P, Collins CL, et al. Computerized neurocognitive testing for the management of sport-related concussions. Pediatrics. 2012 Jan;129(1):38-44.

40. Randolph C, McCrea M, Barr WB. Is neuropsychological testing useful in the management of sportrelated concussion? J Athl Train. 2005;40:139-152.

41. Dessy AM, Yuk FJ, Maniya AY, et al. Review of Assessment Scales for Diagnosing and Monitoring Sports-related Concussion. Cureus. 2017;9(12):e1922.

42. Schatz P, Sandel N. Sensitivity and specificity of the online version of ImPACT in high school and collegiate athletes. Am J Sports Med. 2013;41(2):321-326.

43. Elbin RJ, Schatz P, Covassin T. One-year test-retest reliability of the online version of ImPACT in high school athletes. Am J Sports Med. 2011;39:2319-2324.

44. Iverson GL, Lovell MR, Collins MW. Validity of ImPACT for examining processing speed following sports-related concussion. J Clin Exp Neuropsychol. 2005 Aug;27(6):683-9.

45. World Health Organization (WHO). The ICD-10 Classification of Mental and Behavioural Disorders. https://www.who.int/classifications/icd/en/bluebook.pdf. (1993 accessed 26 April 2021)

46. ImPACT $®$ Applications, Inc. ImPACT ${ }^{\circledR}$ Version 4 Administration and Interpretation Manual. https://impacttest.com/manual/administration-and-scoring-of-impact-version-4/what-is-impactversion-4/. (2021 accessed 26 April 2021).

47. Centers for Disease Control and Prevention, U.S. Department of Health and Human Services. Surveillance Report of Traumatic Brain Injury-related Emergency Department Visits, Hospitalizations, and Deaths-United States, 2014. https://www.cdc.gov/traumaticbraininjury/pdf/TBI-SurveillanceReport-FINAL_508.pdf. (2019 accessed 26 April 2021).

48. Iverson GL, et al. Tracking neurophysiological recovery following concussion in sport. Brain Inj. 2006 Mar;20(3):245-52.

49. Rao DP, et al. Trends in self-reported traumatic brain injury among Canadians, 2005-2014: a repeated cross-sectional analysis. CMAJ Open. 2017:5(2):E301-E307.

50. Centers for Disease Control and Prevention, National Center for Injury Prevention and Control. Report to Congress on mild traumatic brain injury in the United States: steps to prevent a serious public health problem. https://www.cdc.gov/traumaticbraininjury/pdf/mtbireport-a.pdf. (2003 accessed 26 April 2021).

51. Zemek R, Barrowman N, Freedman SB, et al. Pediatric Emergency Research Canada (PERC) Concussion Team. Clinical Risk Score for Persistent Postconcussion Symptoms Among Children With Acute Concussion in the ED. JAMA. 2016 Mar 8;315(10):1014-2.

52. Huang YY, Chen AC, Carroll JD, Hamblin MR. Biphasic dose response in low level light therapy. Dose Response. 2009;7(4):358-383. 
53. Khan I, Arany P. Dosimetry for photobiomodulation therapy: response to Sommers et al. Ann Transl Med. 2016 May; 4(10): 208.

54. Tian F, et al. Transcranial laser stimulation improves human cerebral oxygenation. Lasers Surg Med 2016;48(4):343-349.

55. Nawashiro $\mathrm{H}$, et al. Focal increase in cerebral blood flow after treatment with near-infrared light to the forehead in a patient in a persistent vegetative state. Photomed Laser Surg 2012;30(4):231-233.

56. Naeser MA, Zafonte R, Krengel MH, et al. Significant improvements in cognitive performance posttranscranial, red/near-infrared light-emitting diode treatments in chronic, mild traumatic brain injury: Open-protocol study. J Neurotrauma 2014;31(11):1008-17.

57. de Magalhães MT, et al. Light therapy modulates serotonin levels and blood flow in women with headache. A preliminary study. Exp Biol Med (Maywood) 2016 Jan;241(1):40-5.

58. Lanzafame R. Light Dosing and Tissue Penetration: It Is Complicated. Photobiomodul Photomed Laser Surg. 2020 July; 38(7): 393-394.

59. Jalloh I, Carpenter KL, Helmy A, et al. Glucose metabolism following human traumatic brain injury: methods of assessment and pathophysiological findings. Metab Brain Dis. 2015 Jun;30(3):615-32.

60. Centers for Disease Control and Prevention, U.S. Department of Health and Human Services. Facts about Concussion and Brain Injury Where to Get Help. https://www.cdc.gov/headsup/pdfs/providers/facts_about_concussion_tbi-a.pdf. (2020 accessed 26 April 2021).

61. Brooks B, et al. Subjective, but not Objective, Lingering Effects of Multiple Past Concussions in Adolescents. J Neurotrauma. 2013 Sep 1; 30(17): 1469-1475.

62. Burke MJ, Fralick M, Nejatbakhsh N, et al. In search of evidence-based treatment for concussion: characteristics of current clinical trials. Brain Inj. 2015;29:300-5.

63. Fallesen P, Campos B. Effect of concussion on salary and employment: a population-based event time study using a quasi-experimental design. BMJ Open 2020;10:e038161.

64. Harmon KG, Drezner JA, Gammons M et al. American Medical Society for Sports Medicine position statement: concussion in sport. Br J Sports Med 2013 Jan;47(1):15-26. 